09,03

\title{
Экситонное излучение гетероструктур CdTe/ZnTe c двойными ультратонкими узкозонными слоями
}

\author{
(C) В.Ф. Агекян ${ }^{1}$, А.Ю. Серов ${ }^{1}$, В.А. Сокольников ${ }^{1}$, \\ Н.Г. Философов ${ }^{1}$, G. Karczewski ${ }^{2}$ \\ ${ }^{1}$ Санкт-Петербургский государственный университет, \\ Санкт-Петербург, Россия \\ ${ }^{2}$ Institute of Physics, Polish Academy of Sciences, \\ Warsaw, Poland \\ E-mail: v.agekyan@spbu.ru
}

(Поступила в Редакцию 30 октября 2018 г.)

Исследованы спектры экситонной люминесценции гетероструктур $\mathrm{CdTe} / \mathrm{ZnTe}$, содержащих два тонких слоя CdTe, разделенных барьерами различной толщины. Сложная температурная зависимость интенсивности люминесценции из этих слоев при подбарьерном и надбарьерном способах ее возбуждения позволяет сделать выводы о влиянии толщины барьеров на перенос энергии между слоями СdТе и наблюдать при определенных значениях температуры реализацию возбуждения резонансного типа. Зависимость формы контуров экситонного излучения от уровня возбуждения дает сведения о реальной структуре слоев CdTe толщиной 1.5 и 4.0 монослоя.

Работа поддержана СПбГУ, научная тема № 11.52.454.2016 и National Science Center (Poland), грант № UMO-2017/25/B/ST3/02966.

DOI: 10.21883/FTT.2019.03.47249.297

\section{1. Введение}

Исследование строения и свойств ультратонких [от долей монослоя (MC) до нескольких МC] планарных узкозонных включений, внедренных в полупроводниковую матрицу, дает существенные сведения о практически важных типах гетероструктур. Реальное строение таких систем определяется номинальной толщиной слоев, величиной рассогласования постоянной решетки узкозоного слоя и матрицы, а также технологическими условиями, от которых, в частности, зависит величина атомной диффузии в направлении роста гетероструктуры. Ультратонкий слой может быть как однородным, так и состоящим из ансамбля островков - плоских квантовых точек с различными латеральными размерами. Прямым методом для изучения строения слоев является просвечивающая электронная микроскопия. Применение оптических методов позволяет не только изучать реальное строение слоев, но и получить сведения о переносе энергии и динамике фотоносителей и экситонов. К настоящему времени проведено значительное количество исследований оптических свойств гетероструктур с ультратонкими слоями на основе полупроводников групп III-V и II-VI, в том числе типа $\mathrm{CdSe} / \mathrm{ZnSe}, \mathrm{CdTe} / \mathrm{ZnTe}$, а также гетероструктур II-VI с магнитными компонентами [1-12]. Целью нашей работы является изучение переноса энергии и излучательных свойств экситонов в гетероструктурах, содержащих два слоя CdTe, разделенных барьерами ZnTe различной толщины.

\section{2. Описание образцов}

Исследована серия гетероструктур CdTe/ZnTe, каждая из которых содержит два слоя CdTe $L_{1}$ и $L_{2}$ с номинальными толщинами 1.5 и 4 монослоя (MC), которые разделены барьерами ZnTe с толщинами 15 , 25, 35, 45 и $55 \mathrm{MC}$ (образцы № 1-5 соответственно). На подложках из полуизолирующего $\mathrm{GaAs}\langle 100\rangle$ были выращены последовательно: слой ZnTe толщиной от 4 до $5 \mu \mathrm{m}$; слой СdTe толщиной $1.5 \mathrm{MC}$; барьерный слой ZnTe; слой CdTe толщиной $4 \mathrm{MC}$; покровный слой $\mathrm{ZnTe}$ толщиной $0.05 \mu \mathrm{m}$. Для формирования слоев $\mathrm{CdTe}$ применялась техника атомного наслаивания (ALD) при температуре $440^{\circ} \mathrm{C}$, слои $\mathrm{ZnTe}$ выращивались методом молекулярной пучковой эпитаксии (MBE).

\section{3. Результаты и их обсуждение}

На рис. 1 приведены спектры излучения образцов № 1-5 при надбарьерном возбуждении непрерывным лазером и $T=5 \mathrm{~K}$. Видно, что спектральное положение экситонного излучения слоев $L_{1}$ и $L_{2}$ зависит от расстояния между слоями, наибольшие энергии локализации относительно экситона барьера ZnTe имеют место в образце с толщиной барьера $35 \mathrm{MC}$. Ширины контуров полос излучения экситонов $L_{2}$ на половине их высоты (FWHM) составляют от 10 до $20 \mathrm{meV}$, наименьшие значения FWHM наблюдаются в образцах с максимальным и минимальным расстоянием между слоями $L_{1}$ и $L_{2}$. Величина FWHM контуров излучения экситонов $L_{1}$ составляет от 2 до $4 \mathrm{meV}$, это указывает на значительно 


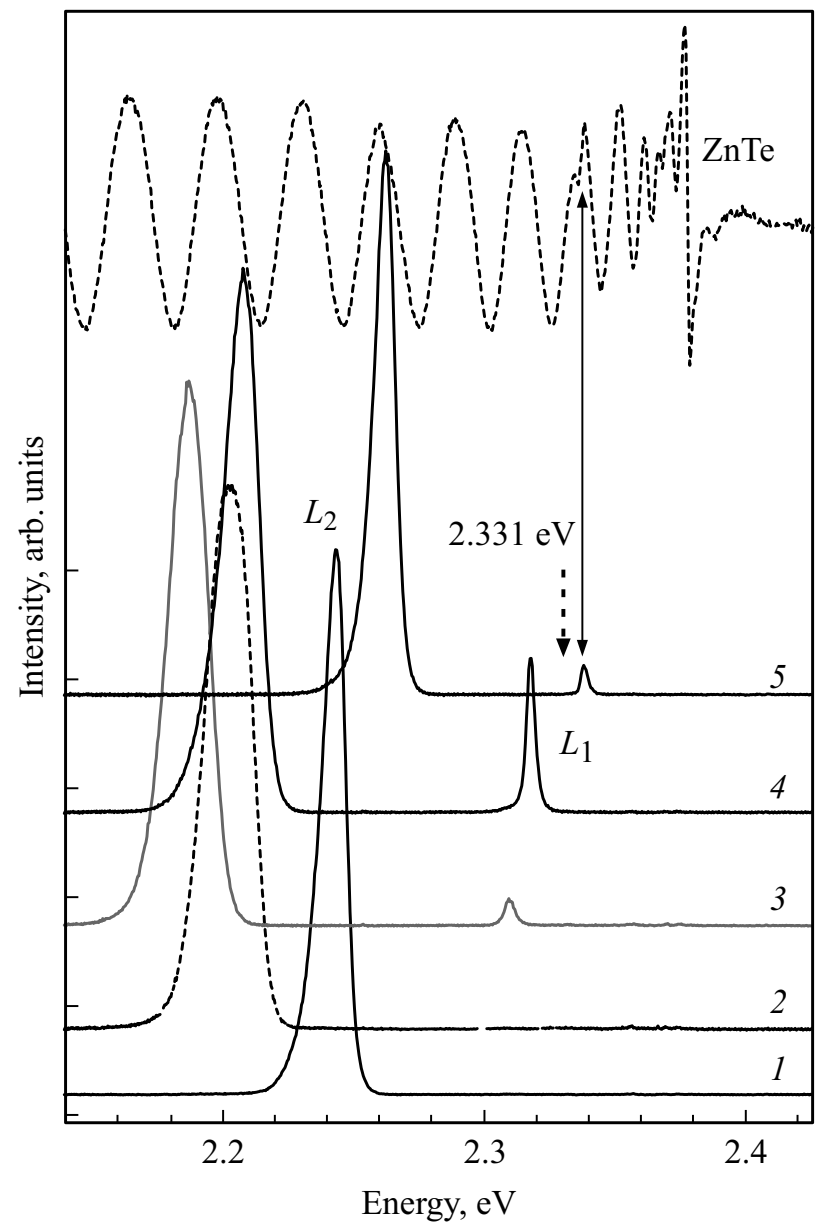

Рис. 1. Спектры излучения экситонов узкозонных слоев CdTe $L_{1}$ и $L_{2}$, внедренных в матрицу ZnTe, в образцах № 1-5 при надбарьерном возбуждении с энергией фотонов $2.81 \mathrm{eV}$, $T=5 \mathrm{~K}$. Штриховой линией показан спектр отражения образца № 5, в котором наблюдаются экситонные резонансы ZnTe и слоя $L_{1}$, а также интерференционные полосы. Пунктирной стрелкой обозначена энергия фотонов, которая использовалась при подбарьерном возбуждении.

бо́льшую однородность слоя $L_{1}$. От расстояния между слоями $L_{1}$ и $L_{2}$ зависят степень перекрытия волновых функций экситонов $L_{1}$ и $L_{2}$ и величины механических напряжений в области каждого узкозонного слоя. Эти факторы, в свою очередь, влияют на энергию оптических переходов и ширину контуров излучения экситонов. Отметим, что исследование влияния толщины барьерного слоя на люминесценцию структуры $\mathrm{CdTe} / \mathrm{ZnTe}$ с более толстыми узкозонными слоями проведено в работе [12].

Толщины слоев $L_{1}$ и $L_{2}$ на порядок меньше, чем размеры экситона, так что экситоны, локализованные на слоях CdTe, принадлежат матрице ZnTe. Толщины барьеров составляют от 1 до 4 радиусов экситона $\mathrm{ZnTe}$, так что на параметры локализации экситона на одном из узкозонных слоев существенно влияет другой узкозонный слой.
Температурная зависимость интенсивности экситонной люминесценции слоя $L_{2}$ в образцах № 1 и № 5 в условиях надбарьерного возбуждения является монотонной, в то время как в образцах № 2-4 максимальная интенсивность достигается в области $40-50 \mathrm{~K}$

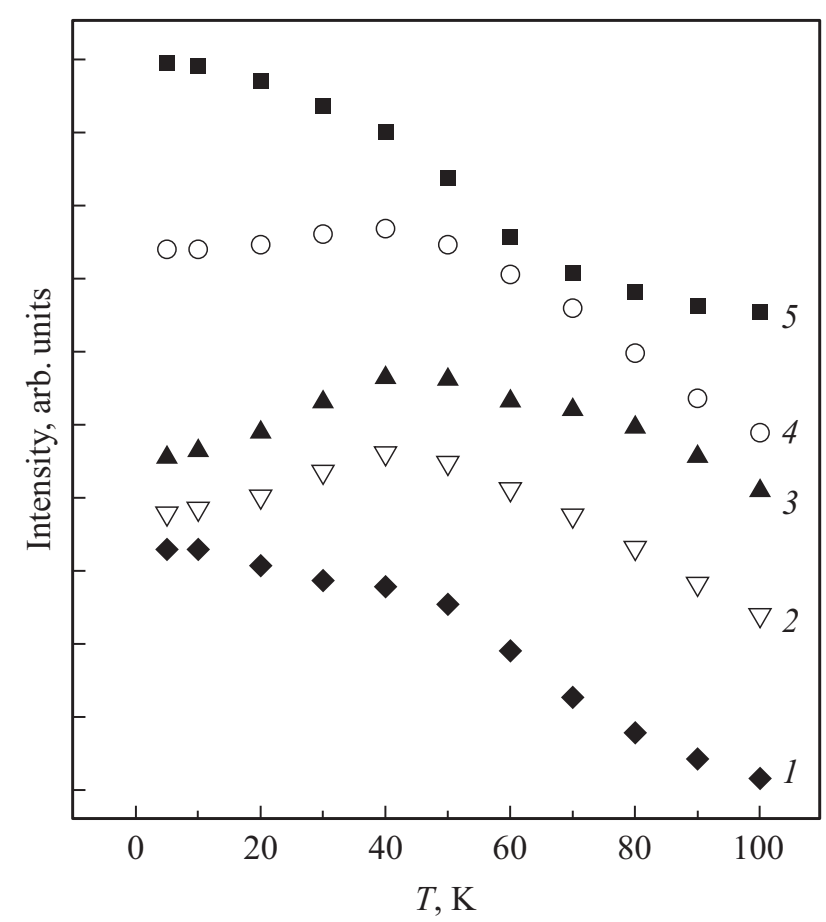

Рис. 2. Температурная зависимость пиковой интенсивности люминесценции экситонов, локализованных на слое $L_{2}$, при надбарьерном возбуждении в образцах №1-5.

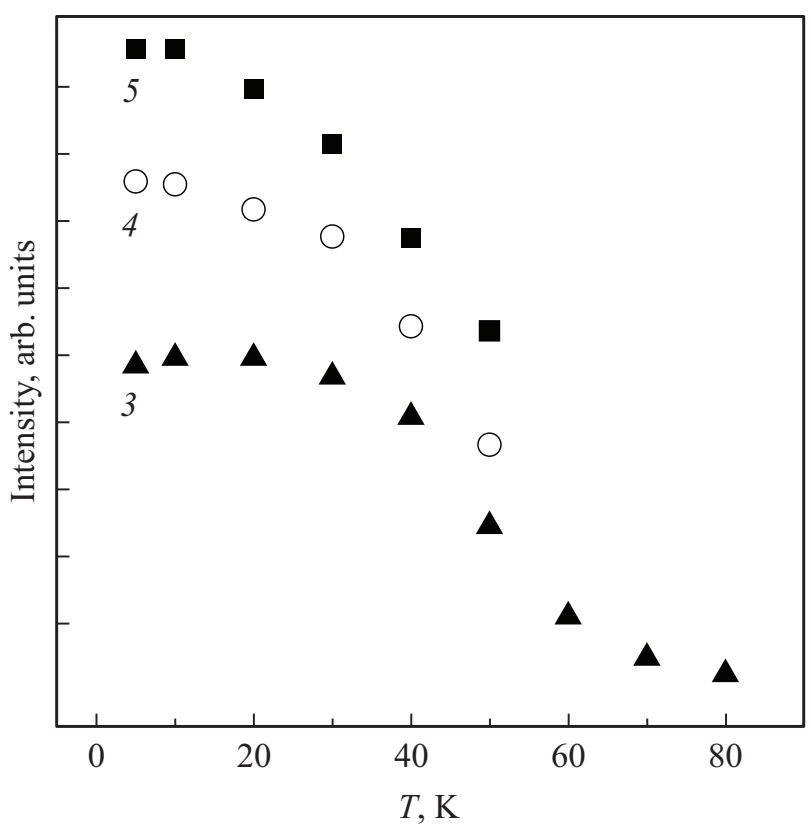

Рис. 3. Температурная зависимость пиковой интенсивности люминесценции экситонов, локализованных на слое $L_{1}$, при надбарьерном возбуждении в образцах № $3-5$. 


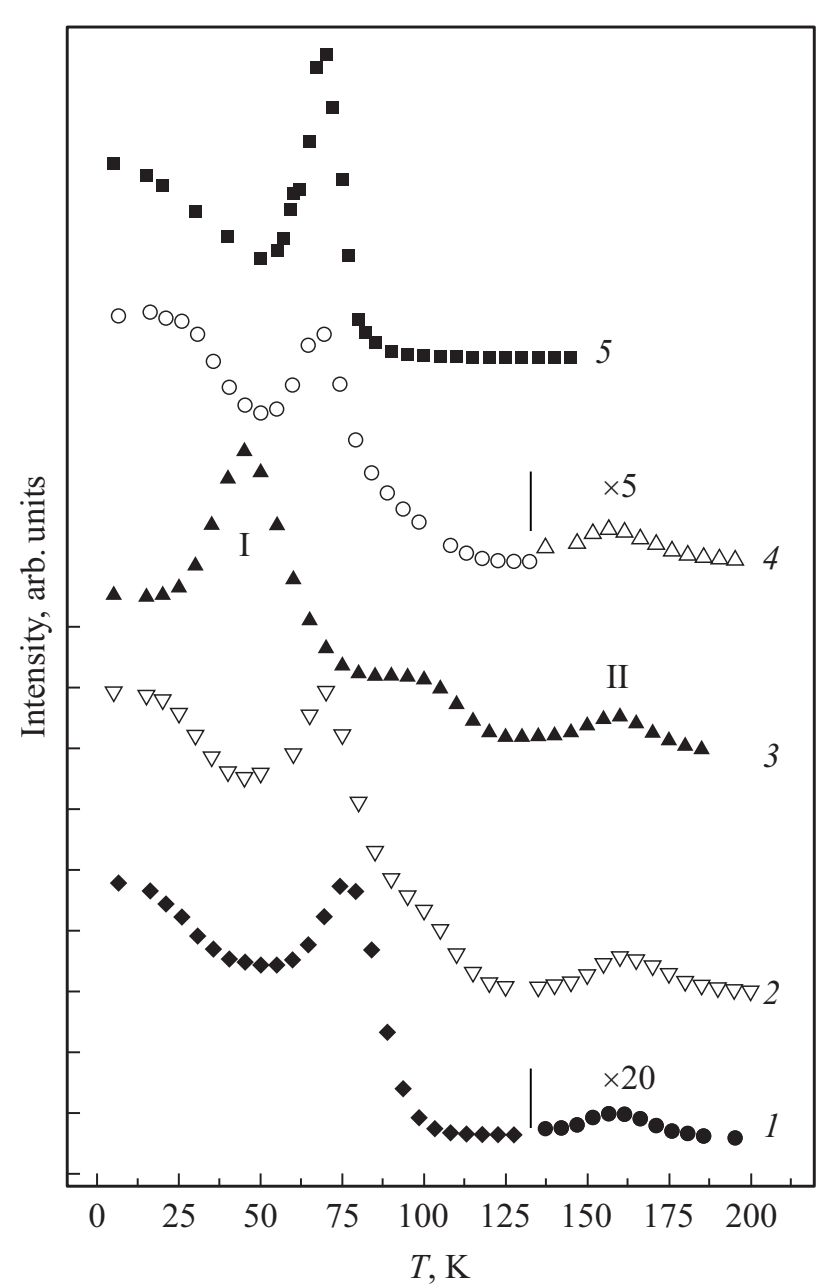

Рис. 4. Температурная зависимость пиковой интенсивности люминесценции экситонов, локализованных на слое $L_{2}$, при подбарьерном возбуждении с энергией квантов $2.331 \mathrm{eV}$ (см. рис. 1) в образцах № 1-5. Происхождение максимумов I и II обсуждается в тексте статьи.

(рис. 2). Это можно объяснить следующим образом. В образцах № 2-4 повышение температуры инициирует перенос экситонов и свободных носителей из слоя $L_{1}$ в слой $L_{2}$. В образце с самым тонким барьером перенос эффективен уже при низких температурах, а в образце с самым толстым барьером деградация излучения слоя $L_{2}$ с температурой не восполняется переносом из слоя $L_{1}$. Различия в температурной зависимости люминесценции слоев $L_{2}$ в образцах № 2-4 и № 1, 5 указывают на то что, она определяется именно переносом из слоев L1, a не из матрицы ZnTe. Температурное ослабление люминесценции экситонов $L_{1}$ является монотонным (рис. 3). Этим подтверждается, что температурный максимум в излучении слоя $L_{2}$ возникает вследствие переноса экситонов и фотоносителей из слоя $L_{1}$, а не из барьера $\mathrm{ZnTe}$.

При подбарьерном возбуждении с энергией фотонов $h v_{0}=2.331 \mathrm{eV}$ температурная зависимость экситонного излучения слоев $L_{2}$ является значительно более сложной (рис. 4). Она определяется температурным сдвигом уровней энергии экситонов слоя $L_{1}$ и матрицы $\mathrm{ZnTe}$ относительно $h v_{0}$. При достижении определенной температуры, $h v_{0}$ совпадает с энергией экситонного резонанса или же отличается от него на энергию одного или двух продольных оптических фононов решетки $\mathrm{ZnTe}$, и это приводит к повышению эффективности оптического возбуждения.

Рассмотрим температурную зависимость пикового значения люминесценции экситона $L_{2}$ на примере образца № 3. Можно выделить четыре характерных участка: максимум I при $50 \mathrm{~K}$; плато около 100 и $130 \mathrm{~K}$ и максимум II при $160 \mathrm{~K}$. При больших плотностях мощности возбуждения удается наблюдать люминесценцию экситонов обоих слоев $L_{1}$ и $L_{2}$ и $\mathrm{ZnTe}$ вплоть до высоких температур. Оказалось, что максимум II соответствует температуре, при которой энергия барьерного экситона $\mathrm{ZnTe}$ совпадает с энергией лазера $h v_{0}$. Максимум I возникает, когда энергия экситона $L_{1}$ становится меньше $h v_{0}$ на энергию LO фонона решетки ZnTe равную $26 \mathrm{meV}$. Плато в области $100 \mathrm{~K}$ соответствует разнице энергий экситона барьера и $h v_{0}$ равной энергии LO фонона, плато в области $130 \mathrm{~K}$ соответствует разнице энергий экситона $L_{1}$ и $h v_{0}$ равной удвоенной энергии LO фонона. Подобные особенности, связанные с резонансными условиями возбуждения, наблюдаются в температурной зависимости люминесценции экситона $L_{2}$ для всех образцов, в частности, максимум I для образцов № 1 и № 5 связан с совпадением энергии экситона $L_{1} \mathrm{c} h v_{0}$.

Зависимость формы контуров экситонного излучения слоев $L_{1}$ и $L_{2}$ от уровня оптического возбуждения демонстрирует различия в реальном строении этих слоев. При повышении плотности мощности надбарьерного

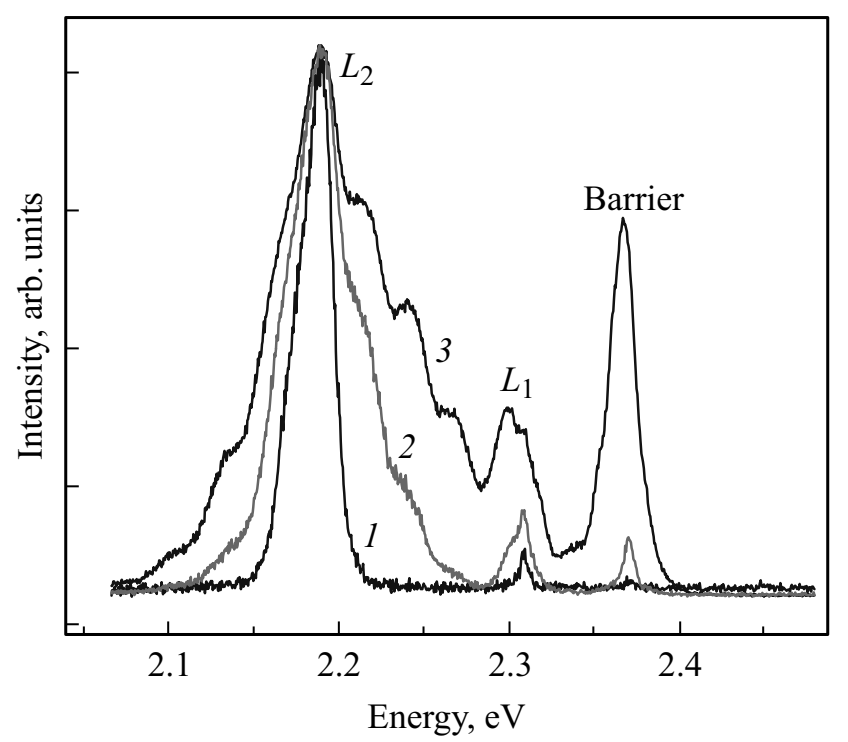

Рис. 5. Нормированные спектры люминесценции образца № 3 при плотностях мощности надбарьерного возбуждения около $1(1), 10(2)$ и $100(3) \mathrm{kW} / \mathrm{cm}^{2}$ (импульсное возбуждение с энергией фотонов $3.68 \mathrm{eV}), T=5 \mathrm{~K}$. Спектры промодулированы полосами интерференции. 
возбуждения образца № 3 от 1 до $100 \mathrm{~kW} / \mathrm{cm}^{2}$ полоса $L_{1}$ уширяется незначительно, в то время как полоса $L_{2}$ становится сильно асимметричной и распространяется в область высоких энергий вплоть до энергии экситона $L_{1}$ (рис. 4). Можно сделать вывод, что слой $L_{2}$ является ансамблем наноостровков с сильной латеральной размерной дисперсией, в то время как более тонкий слой $L_{1}$ представляет собой однородный слой твердого раствора CdZnTe. Плоские квантовые точки слоя $L_{2}$ связаны между собой, так что в условиях слабого оптического возбуждения фотоносители и экситоны релаксируют на островки большого размера. При сильном оптическом возбуждении эти состояния насыщаются, и оптически активными становятся островки меньших размеров, которым соответствует меньшая энергия локализации экситона относительно уровня экситона $\mathrm{ZnTe}$. O насыщении слоев $L_{1}$ и $L_{2}$ свидетельствует появление экситонной люминесценции $\mathrm{ZnTe}$ которая не наблюдается при слабом оптическом возбуждении.

Благодаря малой толщине и однородности слоя $L_{1}$ соответствующий ему экситонный резонанс хорошо наблюдается в спектрах отражения (см. рис. 1), в то время как экситон более мощного островкового слоя $L_{2}$ в отражении проявляется слабо.

\section{4. Заключение}

При различных температурах и уровнях оптического возбуждения исследована экситонная люминесценция гетероструктур CdTe/ZnTe, содержащих два слоя CdTe c номинальной толщиной 1.5 и $4 \mathrm{MC}$, которые разделены барьерами ZnTe различной толщины. Установлено, что более тонкий слой CdTe является однородным, в то время как более толстый слой состоит из плоских островков со значительной латеральной размерной дисперсией. В условиях подбарьерного возбуждения с энергией фотонов $2.331 \mathrm{eV}$ при некоторых значениях температуры реализуется резонансное возбуждение экситонов, приводящее к увеличению квантового выхода люминесценции.

\section{Список литературы}

[1] P. Paki, R. Leonelli, L. Isnard, R.A. Masut. Appl. Phys. Lett. 74, 1445 (1999).

[2] V.S. Bagaev, V.V. Zaytsev, V.V. Kalinin, S.R. Okyabrskii, A.F. Plotnikov. Solid State Commun. 88, 777 (1993).

[3] Z. Wilamowski, W. Jantsch, W. Faschinger. J. Magn. Magn. Mater. 140-144, 1697 (1995).

[4] G. Prechtl, W. Heiss, S. Mackowski, A. Bonanni, G. Karczewski, H. Sitter, W. Jantsch. Semicond. Sci. Technol. 15, 506 (2000).

[5] Y.S. No, T.W. Kim, H.S. Lee, H.L. Park. Appl. Surf. Sci. 243, 143 (2005).

[6] A.M. Kapitonov, U. Woggon, D. Kayser, D. Hommel, T. Itoh. J. Lumin 112, 177 (2005).

[7] A. Alfaro-Martinez, I. Hernandez-Calderon. Microelectron. J. 39, 594 (2008).
[8] В.Ф. Агекян, P.O. Holtz, G. Karczewski, В.Н. Кац, Е.C. Москаленко, А.Ю. Серов, Н.Г. Философов. ФТП 45, 1353 (2011).

[9] В.Ф. Агекян, Н.А. Грунина, А.Ю. Серов, Н.Г. Философов, G. Karczewski. ФTT 56, 2081 (2014).

[10] A. Reznitsky, M. Eremenko, I.V. Sedova, S.V. Sorokin, S.V. Ivanov. Phys. Status Solidi B 252, 1717 (2015).

[11] Г.В. Будкин, М.В. Еременко, А.Н. Резницкий. ЖЭТФ 151, 870 (2017).

[12] S.Y. Jin, S.Y. Kim, J.C. Choi, H.S. Lee. J. Nanosci. Nanothechnol. 17, 4132 (2017).

Редактор К.В. Емцев 